\title{
Thromboprophylaxis for hip and knee surgery: critical appraisal of rivaroxaban
}

This article was published in the following Dove Press journal:

International Journal of COPD

28 April 2010

Number of times this article has been viewed

\section{Erica Romualdi \\ Francesco Dentali \\ Alessandro Squizzato \\ Walter Ageno}

Department of Clinical Medicine, University of Insubria, Varese, Italy
Correspondence: Walter Ageno Department of Clinical Medicine, University of Insubria, Viale Borri 57,

2I I00 Varese - Italy

Tel +390332 278594

Fax +390332393640

Email agewal@yahoo.com
Abstract: Major orthopedic surgery, including total knee replacement surgery (TKR) and total hip replacement (THR) surgery, is associated with a high risk of venous thromboembolism (VTE). In the absence of prophylactic strategies, the overall incidence of VTE can range between $40 \%$ and $60 \%$. Over the last years, the use of anticoagulant drugs such as unfractionated heparin, warfarin, low molecular weight heparin, and fondaparinux has greatly reduced the incidence of this potentially severe complication. Unfortunately, all these anticoagulant drugs present some drawbacks, such as the need for subcutaneous administration or the necessity of frequent laboratory monitoring. More recently, a number of alternative anticoagulant agents have been developed for the prevention of VTE in patients undergoing major orthopedic surgery as well as in other high risk groups. Rivaroxaban, an oral factor Xa inhibitor, has been extensively studied in the setting of major orthopedic surgery. In the RECORD trials program, two studies, RECORD 1 and RECORD 2 were carried out in patients undergoing total hip replacement, and two studies, RECORD 3 and RECORD 4 were carried out in patients undergoing total knee replacement. In all these studies, rivaroxaban, at the fixed, daily dose of $10 \mathrm{mg}$, was shown to be more effective than the comparator enoxaparin for the prevention of VTE, with a similar safety profile. Rivaroxaban, which is now approved in many countries for the prevention of VTE in patients undergoing TKR and THR, has the potential to change current clinical practice by simplifying anticoagulant prophylaxis strategies, in particular, in this setting, where extended administration of thromboprophylaxis for as much as five weeks after the surgical procedure is required.

Keywords: rivaroxaban; thromboprophylaxis; orthopedic surgery; arthroplasty

\section{Introduction}

Major orthopedic surgery, including total hip replacement surgery (THR) and total knee replacement surgery (TKR), is associated with a high risk of venous thromboembolism (VTE). In studies where venography was routinely performed in all patients undergoing THR or TKR but not receiving thromboprophylaxis, the incidence of deep vein thrombosis (DVT) was between $40 \%$ and $60 \% .{ }^{1}$ Although most of these thrombi are clinically silent and tend to solve spontaneously without further complication, there is a substantial risk of complete vein occlusion or embolization to the lungs. ${ }^{1}$ Furthermore, most symptomatic DVT occur after hospital discharge, because the risk of VTE in this setting remains high for at least 2 months after surgery. ${ }^{1,2}$ Because it is impossible to correctly identify which patients will develop symptomatic DVT, the use of thromboprophylaxis becomes necessary in all patients undergoing major orthopedic surgery. ${ }^{1}$ The 2008 guidelines of the American College of Chest Physicians (ACCP) Consensus Conference On Antithrombotic And Thrombolytic Therapies recommend 
administering VTE prophylaxis with either low molecular weight heparin (LMWH), fondaparinux, or warfarin for at least 10 days to all patients undergoing THR and TKR, and extending the administration of prophylactic treatment for up to 35 days after the surgical procedure. ${ }^{1}$ This last recommendation has a higher grade for patients undergoing THR than for those undergoing TKR. ${ }^{1}$

However, these recommendations are not regularly followed: the multinational Global Orthopedic Registry showed that less than $90 \%$ of patients undergoing THR or TKR received some form of ACCP-recommended prophylaxis, and that 7 days after THR, 26\% of patients were no longer receiving prophylaxis. By day 28 , only $46 \%$ of patients were still receiving prophylactic treatment. ${ }^{3,4}$ This difference between the guidelines and clinical practice can be explained in part by some of the limitations of the available anticoagulant drugs. LMWH and fondaparinux need subcutaneous administration, which may present a problem after the patient is discharged, when the assistance of a health care professional may be required to administer the drug. ${ }^{5}$ Furthermore, LMWH is associated with the risk of heparin-induced thrombocytopenia, which requires monitoring the platelet count during treatment. Warfarin has an oral route of administration, but is less effective than $\mathrm{LMWH}-$ at least in TKR surgery - and requires regular monitoring to maintain the international normalized ratio (INR) within the therapeutic range. In addition, the managing of warfarin is complicated by several food and drug interactions, unpredictable pharmacological effects, and intra-patient variability. ${ }^{1}$

Because of the increasing number of patients undergoing major orthopedic surgery, as a consequence of the rapid aging of the population, and because of the tendency to greatly reduce the duration of hospitalization after many surgical procedures, ${ }^{6}$ there is certainly room for improvement in the anticoagulant armamentarium for the prevention of VTE in high-risk patients. Ideal characteristics of the new anticoagulants include better efficacy and improved safety, the availability of fixed doses, the absence of food or drug interactions, a rapid onset and offset of action, and, finally, a more convenient route of administration. Over the last few years, research has thus been guided by the need for convenient administration with predictable pharmacokinetics (PK), pharmacodynamics (PD), and a wide therapeutic window that would permit fixed dosing without requiring coagulation monitoring. This research has focused, in particular, on targeting thrombin (Factor IIa) and Factor Xa (FXa), which are common to both the intrinsic and extrinsic coagulation pathways. Rivaroxaban is the first of a new class of oral Factor Xa inhibitors.

\section{Rivaroxaban}

Rivaroxaban (BAY 59-7939) is a potent and selective oral FXa inhibitor whose particular chemical structure plays a role in the oral absorption of the drug, with a relatively high bioavility. ${ }^{7}$ The drug inhibits not only free FXa, but also prothrombinase activity and clot-associated FXa activity; this would prevent clot-associated FXa from activating prothrombin and thereby contributing to the propagation of thrombosis. ${ }^{8,9}$ Rivaroxaban is well tolerated, has a rapid onset of action with a predictable dose-proportional PD and PK, ${ }^{10}$ its half-life is about 5-9 hours, and it has predominantly renal excretion, though it is also expelled via the faecal/biliar route. ${ }^{11}$ Co-administration with food intake only slightly increases peak plasma concentrations of rivaroxaban, ${ }^{11}$ and only low potential interactions with other drugs have been shown. ${ }^{12}$ Phase I studies demonstrated that gender and body weight did not have clinically-relevant influences on the PK and PD of rivaroxaban in healthy subjects, suggesting that this drug could be administered at a fixed dose to any patient. $^{13,14}$

In phase II dose-finding studies, rivaroxaban was compared with enoxaparin for the prevention of VTE in patients undergoing THR and TKR. ${ }^{15-17}$ In two studies rivaroxaban was administered twice a day with a total daily dose ranging from $5 \mathrm{mg}$ to $60 \mathrm{mg},{ }^{15,16}$ and in a subsequent study ${ }^{17}$ rivaroxaban was given once a day with a whole dosage of 5-40 mg. Overall, rivaroxaban was well tolerated by the patients, and daily dosages of 5-20 mg showed efficacy and tolerability similar to those of enoxaparin. On the basis of these results, the daily dose of $10 \mathrm{mg}$ of rivaroxaban was selected for subsequent phase III studies.

\section{RECORD program}

The RECORD (REgulation of Coagulation in major Orthopedic surgery reducing the Risk of DVT and PE) program comprised four phase III clinical trials: two trials were carried out in patients undergoing THR (RECORD 1 and 2), ${ }^{18,19}$ and two trials were carried out in patients undergoing TKR (RECORD 3 and 4). ${ }^{20,21}$

The RECORD 1 triall $^{18}$ is a randomized double-blind double-dummy study designed to compare rivaroxaban (10 mg once daily), with enoxaparin (40 mg once daily), for 31 to 39 days (extended prophylaxis) in patients undergoing THR. Treatment with rivaroxaban was started 6-8 hours after surgery, whereas treatment with enoxaparin was initiated 
12 hours before surgery and then resumed 6-8 hours after the end of the surgery. A venography was performed the day after the last dose of the study medication (day 32-40), and patients were followed up for a further 30-35 days (Table 1). The primary efficacy outcome (total VTE) was the composite of any DVT, nonfatal pulmonary embolism (PE), or death resulting from any cause, up to 30-42 days. The secondary efficacy outcomes were major VTE, composed of proximal DVT, nonfatal PE, and death from VTE; symptomatic VTE during treatment or follow-up; proximal or distal DVT and death during the follow up period. The incidence of total VTE was significantly reduced from $3.7 \%$ in the group of patients receiving enoxaparin to $1.1 \%$ in the group of patients receiving rivaroxaban (relative risk reduction (RRR) $70 \%$, $P<0.001)$. The incidence of major VTE was $2 \%$ and $0.2 \%$ respectively (RRR $88 \%, P<0.001$ ). Finally, symptomatic VTE occurred in $0.5 \%$ of patients in the enoxaparin group and in $0.3 \%$ of the rivaroxaban group $(P=0.22)$. (Table 2 )

The RECORD 2 study $^{19}$ had a similar design and the same end-points as the RECORD 1 study. The difference between the two studies was in the duration of treatment with the two study drugs: rivaroxaban was administered for 31-39 days while enoxaparin was administered for 10-14 days and then followed by placebo until 31-39 days after surgery (Table 1).

The primary efficacy outcome of total VTE, which was judged at the end of treatment with rivaroxaban or placebo, occurred in $2 \%$ of patients in the rivaroxaban group and in $9.3 \%$ of patients in the enoxaparin group, with a RRR of $79 \%$ ( $P<0.0001)$. Rivaroxaban also significantly reduced the incidence of major VTE $(0.6 \%$ vs $5.1 \%$ respectively, RRR $88 \%, P<0.0001)$ and of symptomatic VTE $(0.2 \%$ and $1.2 \%$ respectively, RRR $80 \%, P=0.004$ ). (Table 2)

RECORD $3{ }^{20}$ and RECORD $4{ }^{21}$ were designed to compare rivaroxaban and enoxaparin in patients undergoing TKR. In both studies, rivaroxaban was administered at the usual $10 \mathrm{mg}$ daily dose started postoperatively. In RECORD 3, the comparator enoxaparin was administered at the dose of $40 \mathrm{mg}$ daily started preoperatively, while in RECORD 4 it was administered at the dose of $30 \mathrm{mg}$ twice a day started postoperatively (Table 1). All patients received treatment for 10-14 days as recommended by the ACCP guidelines at the time when the studies were being planned (2004 guidelines). ${ }^{22}$ In both studies primary and secondary endpoints were the same as in the previous studies.

In RECORD 3 total VTE occurred in $9.6 \%$ of patients in the rivaroxaban group and in $18.9 \%$ of the enoxaparin group (RRR 49\%, $P<0.0001$ ); major VTE occurred in $1 \%$ and $2.6 \%$ of patients respectively $(\mathrm{RRR}=62 \%, P=0.010)$; and symptomatic VTE occurred in $2 \%$ and $0.7 \%$ of patients respectively (RRR 66\%, $P=0.005 \%$ ). (Table 2)

Finally, in RECORD $4^{21}$ total VTE was significantly reduced from $10.1 \%$ in the group receiving enoxaparin to $6.9 \%$ in the group receiving rivaroxaban (RRR 31\%, $P=0.012$ ). There was no statistically significant difference between the rates of major VTE $(2.0 \%$ and $1.2 \%)$ and symptomatic VTE $(1.2 \%$ and $0.7 \%$ respectively) between the two groups (Table 2).

\section{Safety and tolerability}

Safety end-points were the same in all four trials: major bleeding was defined as bleeding occurring after the administration of the first dose of the study medication and less than 2 days after the last dose of the study medication. Major bleeding was defined as bleeding that was fatal, involved a critical organ or required reoperation, or clinically overt bleeding outside the surgical site that was associated with a decrease in the hemoglobin levels of $\geq 2 \mathrm{~g} / \mathrm{dL}$ or requiring an infusion of $\geq 2$ units of blood. Nonmajor bleeding events, including hemorrhagic wound complications (excessive wound hematoma or bleeding at the surgical site). Other adverse events, and deaths were also documented.

In RECORD 1, the incidence of major bleeding was similar between the two groups: $0.3 \%$ in the rivaroxaban group and

Table I The RECORD program

\begin{tabular}{|c|c|c|c|c|}
\hline \multirow[t]{2}{*}{ Study } & \multirow[t]{2}{*}{ Procedure } & \multirow[t]{2}{*}{$\mathbf{N}^{\mathbf{a}}$} & \multicolumn{2}{|c|}{ Duration of therapy } \\
\hline & & & Rivaroxaban & Enoxaparin \\
\hline RECORDI & Total hip replacement & 4,541 & $31-39$ days & $31-39$ days $^{b}$ \\
\hline RECORD2 & Total hip replacement & 2,509 & $31-39$ days & $\begin{array}{l}\text { I0-1 } 4 \text { days, followed by placebo } \\
\text { up to } 31-39 \text { days }^{b}\end{array}$ \\
\hline RECORD3 & Total knee replacement & 2,531 & 10-14 days & $10-14$ days $^{\mathrm{b}}$ \\
\hline RECORD4 & Total knee replacement & 3,148 & 10-14 days & $10-14$ days $^{\mathrm{c}}$ \\
\hline
\end{tabular}

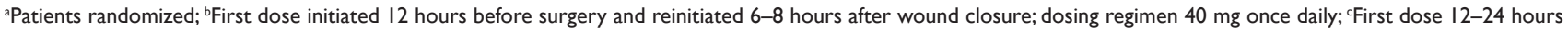
after wound closure; dosing regimen $30 \mathrm{mg}$ twice daily. 


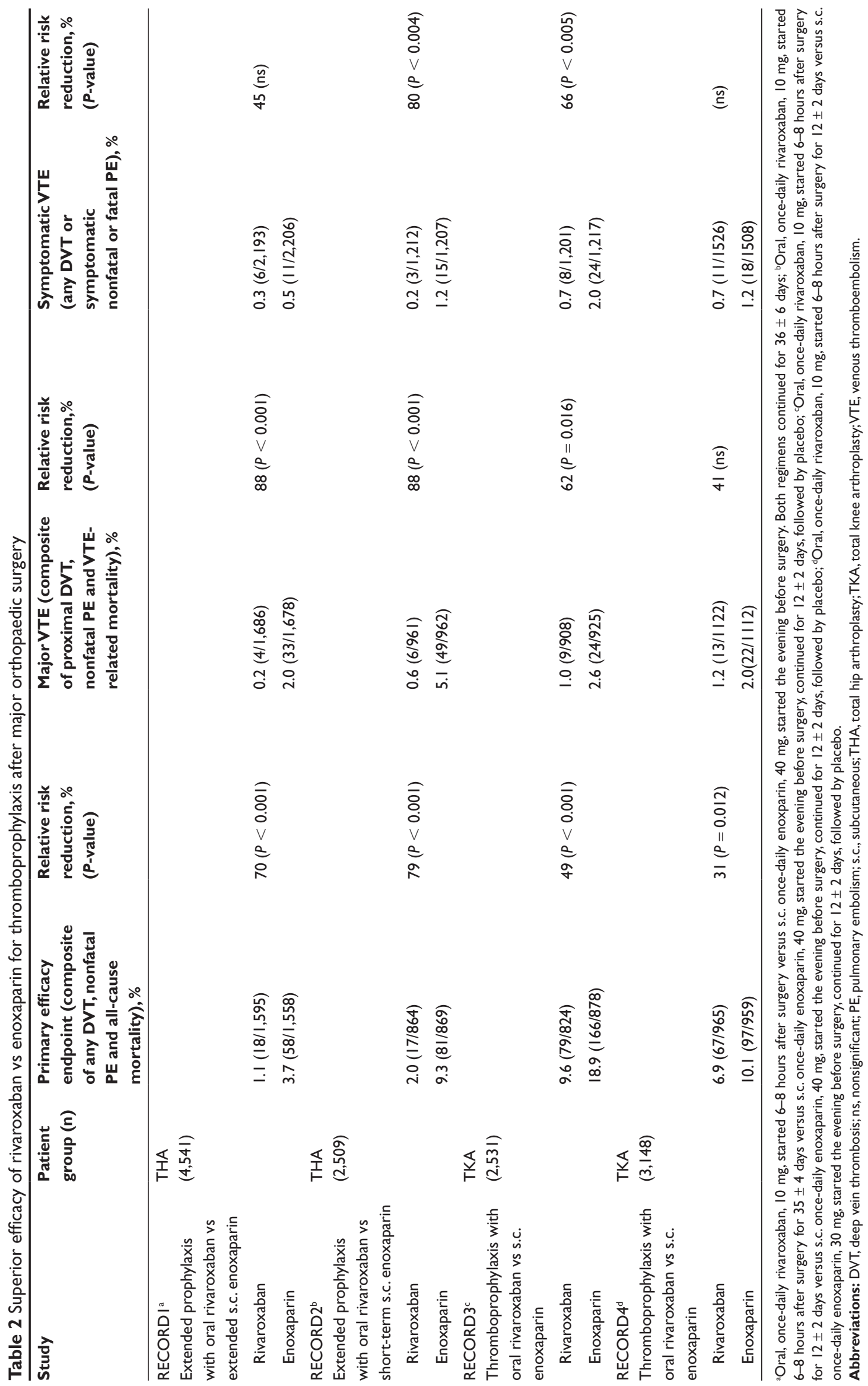


$0.1 \%$ in the enoxaparin group $(P=0.18)$; hemorrhagic wound complications occurred in $1.5 \%$ of patients on rivaroxaban and in $1.7 \%$ of patients on enoxaparin (Table 3 ). During treatment period, the incidence of cardiovascular events was $0.2 \%$ in patients receiving rivaroxaban and $0.4 \%$ in patients receiving enoxaparin; during follow up this incidence was $0.3 \%$ and $<0.1 \%$, respectively. A total of 5 deaths occurred in each group during the entire study period. The occurrence of increased transaminase levels was similar in the two groups. ${ }^{18}$

In the RECORD 2 study, major bleeding occurred in only 1 patient in each group; there was also no difference between groups in the rate of hemorrhagic wound complications (Table 3). Three patients had a cardiovascular event during rivaroxaban treatment and 4 during enoxaparin treatment $(0.2 \%$ vs $0.3 \%)$; during follow up, 4 patients in the rivaroxaban group had a cardiovascular event. A total of 11 deaths occurred during the study: 3 in the group of patients receiving rivaroxaban and 8 in the group of patients receiving short-term prophylaxis with enoxaparin. Similarly to RECORD 1, no signs of liver toxicity were detected. ${ }^{19}$

In RECORD 3, the incidence of major bleeding was $0.5 \%$ in the group of patients treated with enoxaparin and $0.6 \%$ in the group of patients treated with rivaroxaban; there was no statistically significant difference in the incidence of non-major bleeding between the two groups (Table 3 ). During treatment, the incidence of cardiovascular events was similar in the two groups $(0.3 \%$ in the rivaroxaban group and $0.2 \%$ in the enoxaparin); during follow up 7

Table 3 Similar safety profile of rivaroxaban versus enoxaparin for thromboprophylaxis after major orthopedic surgery

\begin{tabular}{|c|c|c|c|c|c|}
\hline \multirow[t]{2}{*}{ Study } & \multirow[t]{2}{*}{ Patient group (n) } & \multicolumn{4}{|c|}{ Safety endpoints, \% (n) } \\
\hline & & Major bleeding & Non-major bleeding & $\begin{array}{l}\text { Post-operative } \\
\text { wound infection }\end{array}$ & $\begin{array}{l}\text { Hemorrhagic } \\
\text { wound } \\
\text { complications }^{\mathrm{a}}\end{array}$ \\
\hline $\begin{array}{l}\text { RECORDI }^{\mathrm{b}} \\
\text { Extended prophylaxis with } \\
\text { oral rivaroxaban }(n=2,209) \text { vs } \\
\text { extended s.c. enoxaparin } \\
(\mathrm{n}=2,224)\end{array}$ & $\begin{array}{l}\text { THA } \\
(4,54 I)\end{array}$ & & & & \\
\hline Rivaroxaban & & $0.3(6)$ & $5.8(128)$ & $0.4(8)$ & $1.5(34)$ \\
\hline Enoxaparin & & $0.1(2)$ & $5.8(129)$ & $0.4(8)$ & $1.7(38)$ \\
\hline $\begin{array}{l}\text { RECORD }{ }^{c} \\
\text { Extended prophylaxis } \\
\text { with oral rivaroxaban }(n=1,228) \text { vs } \\
\text { short-term s.c. } \\
\text { enoxaparin }(n=1,229)\end{array}$ & $\begin{array}{l}\text { THA } \\
(2,509)\end{array}$ & & & & \\
\hline Rivaroxaban & & $<0.1$ (I) & $6.5(80)$ & $0.7(8)$ & $1.6(20)$ \\
\hline Enoxaparin & & $<0.1$ (I) & $5.5(67)$ & $0.5(6)$ & $\mathrm{I} .7(2 \mathrm{I})$ \\
\hline $\begin{array}{l}\text { RECORD } 3^{d} \text { Thromboprophylaxis } \\
\text { with oral rivaroxaban } \\
(n=I, 220) \text { vs s.c. } \\
\text { enoxaparin }(n=I, 239)\end{array}$ & $\begin{array}{l}\text { TKA } \\
(2,531)\end{array}$ & & & & \\
\hline Rivaroxaban & & $0.6(7)$ & $4.3(53)$ & $0.6(7)$ & $2.0(25)$ \\
\hline Enoxaparin & & $0.5(6)$ & $4.4(54)$ & $0.9(\mathrm{II})$ & $1.95(24)$ \\
\hline $\begin{array}{l}\text { RECORD4 }{ }^{\text {Thromboprophylaxis }} \\
\text { with oral rivaroxaban }(n=1,526) \text { vs } \\
\text { s.c. enoxaparin }(n=1,508)\end{array}$ & $\begin{array}{l}\text { TKA } \\
(3,034)\end{array}$ & & & & \\
\hline Rivaroxaban & & $0.7(10)$ & $2.6(39)$ & $0.3(4)$ & $1.4(2 \mathrm{I})$ \\
\hline Enoxaparin & & $0.3(4)$ & $2.0(30)$ & $0.2(3)$ & $1.5(22)$ \\
\hline
\end{tabular}

a Hemorrhagic wound complications = composite of excessive wound hematoma and reported bleeding at surgical site; ${ }^{\circ}$ Oral, once-daily rivaroxaban, $10 \mathrm{mg}$, started $6-8$ hours after surgery versus s.c. once-daily enoxparin, $40 \mathrm{mg}$, started the evening before surgery. Both regimens continued for $36 \pm 6$ days; 'Oral, once-daily rivaroxaban, $10 \mathrm{mg}$, started 6-8 hours after surgery for $35 \pm 4$ days versus s.c. once-daily enoxaparin, $40 \mathrm{mg}$, started the evening before surgery, continued for $12 \pm 2$ days, followed by placebo; $\mathrm{d} O$ ral, once-daily rivaroxaban, $10 \mathrm{mg}$, started 6-8 hours after surgery for $12 \pm 2$ days versus s.c. once-daily enoxaparin, $40 \mathrm{mg}$, started the evening before surgery, continued for $12 \pm$ 2 days, followed by placebo; 'Oral, once-daily rivaroxaban, $10 \mathrm{mg}$, started 6-8 hours after surgery for $12 \pm 2$ days versus s.c. once-daily enoxaparin, $30 \mathrm{mg}$, started the evening before surgery, continued for $12 \pm 2$ days, followed by placebo.

Abbreviations: s.c., subcutaneous; THA, total hip arthroplasty;TKA, total knee arthroplasty. 
events occurred, all in the enoxaparin group. During the study period there were no deaths among patients receiving rivaroxaban and 6 deaths $(0.5 \%)$ in patients receiving enoxaparin. Again, there was no difference in the rate of patients with increased transaminase levels. ${ }^{20}$

Finally, in RECORD $4,0.7 \%$ of the patients in the rivaroxaban group and $0.3 \%$ of patients in the enoxaparin group had a major bleeding event $(P=0.10)$. Nonmajor bleeding occurred in a similar number of patients in the rivaroxaban group $(2.6 \%)$ and in the enoxaparin group (2\%) (Table 3). Cardiovascular events occurred in 7 (0.5\%) patients in the rivaroxaban group and in $11(0.7 \%)$ patients in the enoxaparin group.

\section{Patients' perspectives}

The RECORD program evaluated the efficacy and safety of rivaroxaban, a new, oral direct and selective Factor $\mathrm{Xa}$ inhibitor in the prevention of VTE in more than 12,500 patients undergoing THR and TKR. The results of the RECORD trials are certainly consistent and have led to the approval of rivaroxaban in the European Union, Canada, and several other countries in the world, for the prevention of VTE after elective THR or TKR surgery. Potential advantages for the patients with the use of rivaroxaban derive from the oral route of administration, the availability of a fixed dose that can be administered to all patients irrespective of age or body weight, and the favorable drug-to-drug interaction profile that allows the concomitant administration of other drugs, such as nonsteroidal anti-inflammatory drugs, which are often prescribed to patients undergoing major orthopedic surgery. Although practical advantages are self-evident, translation into daily clinical practice may likely take some time and only reports from clinical practice patterns over the next months and years will tell us the impact of rivaroxaban, as well as of several other new oral anticoagulant agents, in the real world.

In the setting of orthopedic surgery there is an obvious major concern about bleeding risks and overall tolerability. Although data from the RECORD trials are certainly positive, and subgroup analyses from RECORD studies are reassuring, in particular, showing comparable rates of bleeding where patients are on rivaroxaban as compared to enoxaparin regimens across different age, body weight, and renal function groups, we must acknowledge that, as in all phase III studies, patients at the highest risk of bleeding were excluded from the RECORD studies, and some special patient populations, such as elderly patients, or patients with renal insufficiency, were less represented. Indeed, phase IV clinical studies aimed at confirming the safety and tolerability of all such new compounds in the highest risk populations will be most welcome.

Continuing controversies surround the management of bleeding complications during treatment with rivaroxaban. The relatively short half-life and rapid offset of action of the drug should facilitate management, but real antidotes are currently lacking. The administration of blood products (eg, fresh frozen plasma) is currently recommended. Potential differences in patients' compliance when changing from an injectable to an oral drug will also need to be considered.

In conclusion, rivaroxaban is a very effective and well tolerated new anticoagulant drug for the prevention of VTE in patients undergoing THR and TKR. Thanks to its practical advantages, rivaroxaban has the potential to further improve prophylactic strategies in this setting, in particular for extended prophylaxis after discharge of the patient.

\section{Disclosures}

The authors report no conflicts of interest in this work.

\section{References}

1. Geerts WH, Bergqvist D, Pineo GF, et al. Prevention of venous thromboembolism: American College of Chest Physicians evidence-based clinical practice guidelines (8th edition). Chest. 2008;133: 381-453.

2. Kearon C. Natural history of venous thromboembolism. Circulation. 2003;107:122-130.

3. Friedman RJ, Gallus AS, Cushner FD, et al. Physician compliance with guidelines for deep vein thrombosis prevention in total hip and knee arthroplasty. Curr Med Res Opin. 2008;24:87-97.

4. Warwick D, Friedman RJ, Agnelli G. Insufficient duration of venous thromboembolism prophylaxis after total hip or knee replacement when compared with the time course of thromboembolic events: finding from the Global Orthopedic Registry. J Bone Joint Surg Br. 2007;89:799-807.

5. Ansell J, Bergqvist D. Current options in the prevention of thromboembolic disease. Drugs. 2004;64:1-5.

6. Turpie AG. Oral direct Factor Xa inhibitors in development for the prevention and treatment of thromboembolic diseases. Arterioscler Thromb Vasc Biol. 2007;27:1238-1247.

7. Eriksson BI, Quinlan DJ. Oral anticoagulants in development: focus on thromboprophylaxis in patients undergoing orthopedic surgery. Drugs. 2006;66 (11):1411-1429.

8. Perzborn E, Strassburger J, Wilmen A, et al. In vitro and in vivo studies of the novel antithrombotic agent BAY59-7939 an oral direct Factor Xa inhibitor. J Thromb Haemost. 2005;3:514-521.

9. Eisenberg PR, Siegel JE, Abendschein DR, Miletich JP. Importance of factor Xa in determining the procoagulant activity of whole-blood clots. J Clin Invest. 1993;91:1877-1883.

10. Kubitza D, Becka M, Voith B, Zuehlsdorf M, Wensing G. Safety, pharmacodynamics, and pharmacokinetics of BAY 59-7939, an oral direct factor Xa inhibitor. Clin Pharmacol Ther. 2005;78:412-421.

11. Kubitza D, Becka M, Wensing G, Voith B, Zuehlsdorf M. Safety, pharmacodynamics, and pharmacokinetics of BAY 59-7939 - an oral direct factor Xa inhibitor - after multiple dosing in healthy male subjects. Eur J Clin Pharmacol. 2005;61:873-880. 
12. Kubitza D, Haas S. Novel factor Xa inhibitors for the prevention and treatment of thromboembolic diseases. Expert Opin Investig Drugs. 2006;15:843-855.

13. Kubitza D, Becka M, Mueck W, et al. The effect of extreme age, and gender, on the pharmacology and tolerability of rivaroxaban - an oral direct Factor Xa inhibitor. Blood. 2006;108:Abstract 905.

14. Kubitza D, Becka M, Zuehlsdorf M, Mueck W. Effects of a single dose BAY 59-7939 - an oral direct factor Xa inhibitor - in subjects with extreme body weight. Blood. 2005;106:Abstract 1872 .

15. Turpie AG, Fisher WD, Bauer KA, et al. BAY 59-7939: an oral direct factor $\mathrm{Xa}$ inhibitor for the prevention of venous thromboembolism in patients after total knee replacement. A phase II dose-ranging study. J Thromb Haemost. 2005;3:2479-2486.

16. Eriksson BI, Borris L, Dahl OE, et al. Oral direct Factor Xa inhibition with BAY59-7939 for the prevention of venous thromboembolism after total hip replacement. J Thromb Haemost. 2006;4:121-128.

17. Eriksson BI, Borris 1, Dahl OE, et al. A once-daily, oral, direct Factor Xa inhibitor, rivaroxaban (BAY59-7939), for thromboprophylaxis after total hip replacement. Circulation. 2006;114:2374-2381. Epub 2006 Nov 20.
18. Eriksson BI, Borris LC, Friedman RJ, et al. Rivaroxaban versus enoxaparin for thromboprophylaxis after hip arthroplasty. $N$ Engl $J$ Med. 2008;358:2765-2775.

19. Kakkar AK, Brenner B, Dahl OE, et al. Extended duration rivaroxaban versus short-term enoxaparin for the prevention of venous thromboembolism after total hip arthroplasty:a double-blind randomized controlled trial. Lancet. 2008;372:31-39. Epub 2008 Jun 24.

20. Lassen MR, Ageno W, Borris LC, et al. Rivaroxaban versus enoxaparin for thromboprophylaxis after total knee arthroplasty $N$ Engl J Med. 2008;358:2776-2786.

21. Turpie AG, Lassen MR, Davidson BL, et al. Rivaroxaban versus enoxaparin for thromboprophylaxis after total knee arthroplasty (RECORD 4):a randomized trial. Lancet. 2009;373:1673-1680. Epub 2009 May 4.

22. Geerts WH, Pineo GF, Heit JH, et al. Prevention of venous thromboembolism: the Seventh ACCP conference on antithrombotic and thrombolytic therapy. Chest. 2004;126(3 Suppl):338S-400S.
Open Access Surgery

\section{Publish your work in this journal}

Open Access Surgery is an international, peer-reviewed, open access journal that focuses on all aspects of surgical procedures and interventions. Patient care around the peri-operative period and patient outcomes post surgery are key topics. All grades of surgery from minor cosmetic interventions to major surgical procedures are covered. Novel techniques

\section{Dovepress}

and the utilization of new instruments and materials, including implants and prostheses that optimize outcomes constitute major areas of interest. The manuscript management system is completely online and includes a very quick and fair peer-review system. Visit http://www.dovepress.com/ testimonials.php to read real quotes from published authors. 